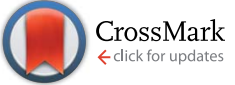

Cite this: RSC Adv., 2015, 5, 61035
Received 27th April 2015

Accepted 9th July 2015

DOI: $10.1039 / c 5 r a 07660 a$

www.rsc.org/advances

\section{Design and structure-property relationship of benzothienoisoindigo in organic field effect transistors $\uparrow$}

\begin{abstract}
Tsukasa Hasegawa, Minoru Ashizawa* and Hidetoshi Matsumoto*
A novel planar $\pi$-conjugated small molecule, benzothienoisoindigo (BTII), in which additional benzene rings are fused with the thieoisoindigo (TII) unit, has been designed and synthesized. We report the impact of the planar $\pi$-framework and $\pi$-conjugation length on the carrier transport properties using three sets of molecules, BTII, isoindigo (II) and TII, bearing the same hexyl-side chain. The absorption spectra are remarkably red-shifted in the order of $\mathrm{II}<\mathrm{TI}<\mathrm{BT}$ II along with the enhanced molar extinction coefficient in the low-energy region, leading to the reduced bandgap. The single-crystal structure analyses revealed that all molecules have a planar backbone, and II and BTII are packed into a slipped columnar structure showing highly one-dimensional $\pi-\pi$ interactions, while TII did not form, any noticeable intermolecular overlaps. The carrier transport properties were investigated in field-effect transistors (FETs). All molecules exhibited typical ambipolar properties. Among them, BTII showed the highest FET p-dominant ambipolar performance with the hole mobility of $0.095 \mathrm{~cm}^{2} \mathrm{~V}^{-1} \mathrm{~s}^{-1}$ and electron mobility of $5.8 \times 10^{-3} \mathrm{~cm}^{2} \mathrm{~V}^{-1} \mathrm{~s}^{-1}$ on the tetratetracontane (TTC)-modified substrate and $p$-type performance with the hole mobility of 0.18 $\mathrm{cm}^{2} \mathrm{~V}^{-1} \mathrm{~s}^{-1}$ on the octadecyltrimethoxysilane (OTMS)-modified substrate. The microstructure of thin films was characterized by X-ray diffraction (XRD) and atomic force microscopy (AFM) measurements. These results indicated that smooth and densely packed nanorod-like crystalline grains are formed by extension of the $\pi$-conjugation in BTII. Due to the $\pi$-extension of planar organic semiconductors, the novel BTII unit can be extended for the rational design of high performance FET materials.
\end{abstract}

\section{Introduction}

Organic semiconductors have been attracting attention due to the advantages of low-cost, large-area printing, mechanical flexibility, and tunable optoelectronic properties for application in organic field effect transistors (OFETs). ${ }^{1-6}$ Their OFET performance has been significantly improved by the rational design of the molecular structure and optimization of the device architecture. $^{7-9}$ In particular, ambipolar materials, which enable hole and electron transport, are very important to realize singlecomponent organic logic circuits ${ }^{10,11}$ and light-emitting transistors $^{12,13}$ as well as the basic understanding of carriertransport behavior in the solid state. To date, the performance of ambipolar polymer semiconductors has been dramatically improved, in which their hole and electron mobilities of $>1 \mathrm{~cm}^{2}$ $\mathrm{V}^{-1} \mathrm{~s}^{-1}$ have been reported. ${ }^{\mathbf{1 4 , 1 5}}$ However, the ambipolar

Department of Organic and Polymeric Materials, Tokyo Institute of Technology, O-okayama 2-12-1, Meguro-ku, Tokyo 152-8552, Japan. E-mail: ashizawa.m.aa@m. titech.ac.jp; matsumoto.h.ac@m.titech.ac.jp

$\dagger$ Electronic supplementary information (ESI) available: Additional information on material synthesis, thermal properties, X-ray single crystal structure analysis, and fabrication and characterization of organic field-effect transistors. CCDC 1061785-1061787. For ESI and crystallographic data in CIF or other electronic format see DOI: 10.1039/c5ra07660a properties of small molecules are still lower than those of polymer semiconductors. Small molecular semiconductors are considered to be promising ambipolar materials due to their advantages of a well-defined molecular structure, high purity, and less batch-to-batch variations compared to polymer semiconductors. ${ }^{16-21}$

Among the building blocks constituting organic semiconductors, isoindigo (II) is well known as an electron-deficient unit realizing a high performance OFET. ${ }^{22}$ II has a slightly twisted structure at the central double bond due to the steric hindrance between the phenyl proton and the carbonyl oxygen. In contrast, thienoisoindigo (TII), in which the benzene rings of the II unit are replaced with thiophenes, is a completely planar unit since the non-bonding sulfur-oxygen interaction removes the steric hindrance to form a flat $\pi$-surface and enhance the charge delocalization coming from the quinoidal structure of the framework. ${ }^{\mathbf{8 3 - 3 5}}$ In a previous study, we reported ambipolar TII-based small molecules, and these molecules displayed wellbalanced hole and electron mobilities of $10^{-2} \mathrm{~cm}^{2} \mathrm{~V}^{-1} \mathrm{~s}^{-1}$ in spite of the one-dimensional $\pi$-system. ${ }^{28}$ These results prompted us to design a more $\pi$-expanded TII-based molecule, benzothienoisoindigo BTII, to ensure strong $\pi-\pi$ intermolecular interactions constructing a dense molecular packing preferable for effective charge-transport. In addition, the relationship 


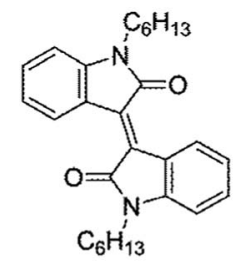

1: tI-C6

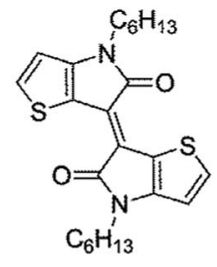

2: TII-C6

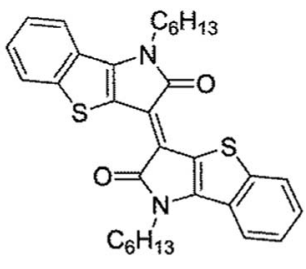

3: BTII-C6
Fig. 1 Chemical structures of 1-3.

between the structure and properties of a $\pi$-conjugated molecules on carrier-transport performance is worthy of being studied systematically.

In the present study, our efforts focus on the impact of the planar and $\pi$-expanded backbone of newly prepared BTII on carrier transport property by comparing those of II and TII derivatives in views of molecular structures, molecular packing motifs, and thin-film microstructures. We now report the OFET performance of II-C6, 1 TII-C6, 2 and BTII-C6, 3 (Fig. 1). Ambipolar characteristics were observed in all devices of 1-3 on the tetratetracontane (TTC)-modified substrate, in which 3 showed the highest mobilities with $\mu_{\mathrm{h}, \max }=0.095 \mathrm{~cm}^{2} \mathrm{~V}^{-1} \mathrm{~s}^{-1}$ and $\mu_{\mathrm{e}, \max }=5.8 \times 10^{-3} \mathrm{~cm}^{2} \mathrm{~V}^{-1} \mathrm{~s}^{-1}$ while the device on the octadecyltrimethoxysilane (OTMS)-modified substrate exhibited p-type performance with $\mu_{\mathrm{h}, \max }=0.18 \mathrm{~cm}^{2} \mathrm{~V}^{-1} \mathrm{~s}^{-1}$. The $\pi$-conjugated framework of 3 enhances intermolecular couplings and makes well-ordered microstructure in thin film, leading to high carrier mobility compared with 1 and 2. Our results provide an insight into the structure-property relationships for high-performance BTII-based semiconductors.

\section{Result and discussion}

\section{Synthesis and characterization}

The synthetic routes of $\mathbf{1}, \mathbf{2}$, and, $\mathbf{3}$ are shown in Scheme S1.† $\mathbf{1}$, 4 and 5 were prepared according to previous reports. ${ }^{27,36,37}$ For the synthesis of 3, the Ullmann-type amination of 3-bromobenzothiophene $\mathbf{5}$ with hexylamine afforded the aminated product 6. The subsequent treatment with oxalyl chloride provided the corresponding isatin 7 . The coupling reaction of isatin 7 using Lawesson's reagent gave compound 3 (Scheme 1). The detailed synthesis procedures are described in the ESI. $\dagger$ The decomposition temperature defined as the $5 \%$ weight loss estimated from a thermal gravimetric analysis (TGA) were 299 ${ }^{\circ} \mathrm{C}$ for $1,296{ }^{\circ} \mathrm{C}$ for 2 and $367{ }^{\circ} \mathrm{C}$ for 3 (Fig. S1 $\dagger$ ). Except for molecule 3 , the melting points were observed at $113^{\circ} \mathrm{C}$ for $\mathbf{1}$ and $122{ }^{\circ} \mathrm{C}$ for 2 . These observations indicated that the extended $\pi$-conjugation of the planar backbone improved the thermal stability, which is probably related to forming the tight intermolecular $\pi-\pi$ stacking due to the enhanced $\pi-\pi$ intermolecular interactions.

\section{Theoretical calculations}

To evaluate the electronic structures and optimized geometries of 1-3, density functional theory (DFT) calculations using the
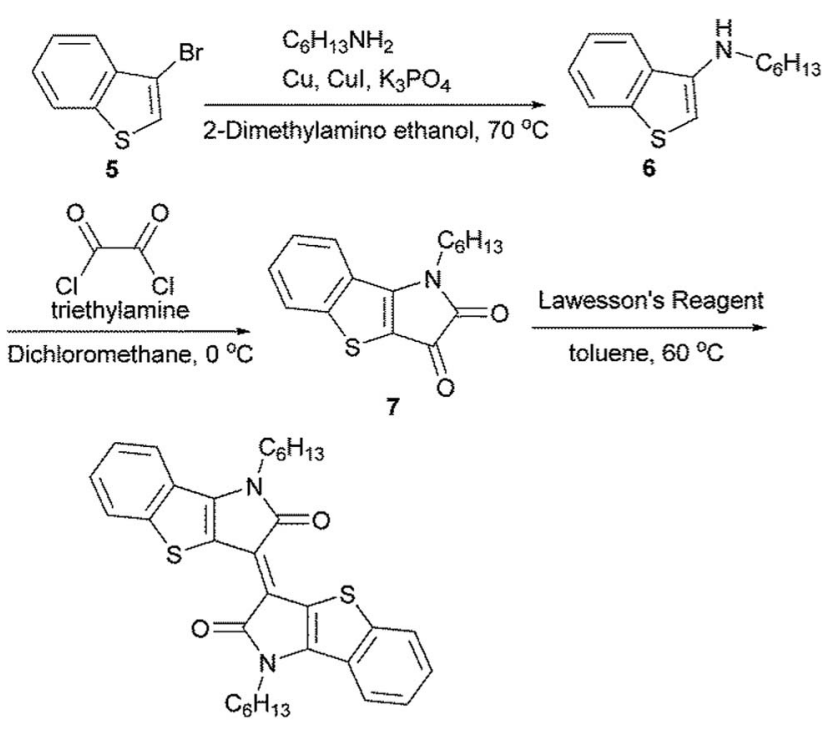

3

Scheme 1 Synthetic route of 3.

Gaussian 09 program based on the B3LYP/6-31G ${ }^{+}(\mathrm{d}, \mathrm{p})$ level have been performed on methyl-substituted molecules. ${ }^{38}$ Fig. 2 shows the energy-minimized structures and the corresponding НОMO and LUMO orbitals of the methyl-substituted 1-3. The optimized molecular geometries of 2 and 3 are completely flat structures, while 1 is twisted by $12.9^{\circ}$ at the central double bond. These results imply that TII and BTII are desirable materials for carrier-transport since a high planar backbone often reinforces the $\pi-\pi$ interactions to form a high crystalline film..$^{30}$ The HOMO and LUMO orbitals of all molecules are well delocalized over the $\pi$-conjugated skeletons. The calculated HOMO and LUMO levels are $-5.89 \mathrm{eV}$ and $-2.99 \mathrm{eV}$ for $\mathbf{1},-5.32 \mathrm{eV}$ and $-2.84 \mathrm{eV}$ for 2 , and $-5.19 \mathrm{eV}$ and $-3.08 \mathrm{eV}$ for 3 , respectively. The high-lying HOMO and low-lying LUMO reduce the bandgap in the order of $\mathbf{1}<\mathbf{2}<\mathbf{3}$.

\section{Optical and electrochemical properties}

The optical and electrochemical properties of 1-3 have been investigated by UV-vis absorption spectroscopy and cyclic voltammetry (CV), and the data are listed in Table 1. Fig. 3 shows the UV-vis absorption spectra of 1-3 in a $10^{-5} \mathrm{M}$ chloroform solution and spin-coated thin films. All molecules exhibited the dual main absorption bands in both a solution and thin film, which consist of relatively strong bands in the high-energy region (350-400 nm for 1 and 2 and $370-470 \mathrm{~nm}$ for 3 ) and broad bands in the low-energy region $(400-550 \mathrm{~nm}$ for $\mathbf{1}$, $450-550 \mathrm{~nm}$ for 2 , and $500-800 \mathrm{~nm}$ for 3 ). The low energy absorption bands in solution were remarkably red-shifted in the order of $\mathbf{1}<\mathbf{2}<\mathbf{3}$ along with the enhanced molar extinction coefficient $\left(\varepsilon_{\max }\right)$, indicating that this observation is basically consistent with the order of the molecular planarity and $\pi$-conjugation length. Compared to the solution spectra, the absorption spectra in the thin films of 2 and 3 showed an obvious red-shift, suggesting a considerable intermolecular 
(a)

aggregation in the solid state. Especially, the appearance of the more structural peaks for $\mathbf{2}$ and $\mathbf{3}$ than that for $\mathbf{1}$ would be due to the flat molecular structures enhancing the intermolecular $\pi-\pi$ interactions. The optical bandgaps $\left(E_{\mathrm{g}}^{\mathrm{opt}}\right)$ estimated from the absorption onset in solution are $2.03 \mathrm{eV}$ for $1,1.88 \mathrm{eV}$ for 2 , and $1.57 \mathrm{eV}$ for 3 , agreeing with the DFT calculation results.

The electrochemical potentials of $E_{\text {Hомо }}$ and $E_{\mathrm{LuMO}}$ were determined from the onset oxidation potentials and reduction potentials of the cyclic voltammograms, which were calibrated by ferrocene/ferrocenium $\left(\mathrm{Fc} / \mathrm{Fc}^{+}\right)$, whose redox potential was assumed to be $-4.8 \mathrm{eV}$ under vacuum level (Fig. 4). ${ }^{39}$ Molecules 1 and 2 exhibited irreversible oxidation and reduction profiles whereas 3 clearly exhibited two separated reversible oxidation and reduction couples. Molecule 2 has higher HOMO and lower LUMO levels by $c a$. $0.2 \mathrm{eV}$ than those of $\mathbf{1}$. This observation is related to the release of the steric twist of $\mathbf{1}$ to form the flat $\pi$-framework of 2 . Of particular note is that $\mathbf{3}$ has a high-lying HOMO level and almost the same LUMO level as 2, suggesting that the $\pi$-extension of $\mathbf{3}$, in which additional phenyl rings are fused to the TII unit, contributes to the increase in the HOMO level without changing the LUMO level. The resulting HOMOLUMO gaps $\left(E_{\mathrm{g}}^{\mathrm{CV}}\right)$ are $2.31 \mathrm{eV}$ for $1,1.86 \mathrm{eV}$ for 2 , and $1.69 \mathrm{eV}$ for 3 , which are consistent with the optical bandgap trend.

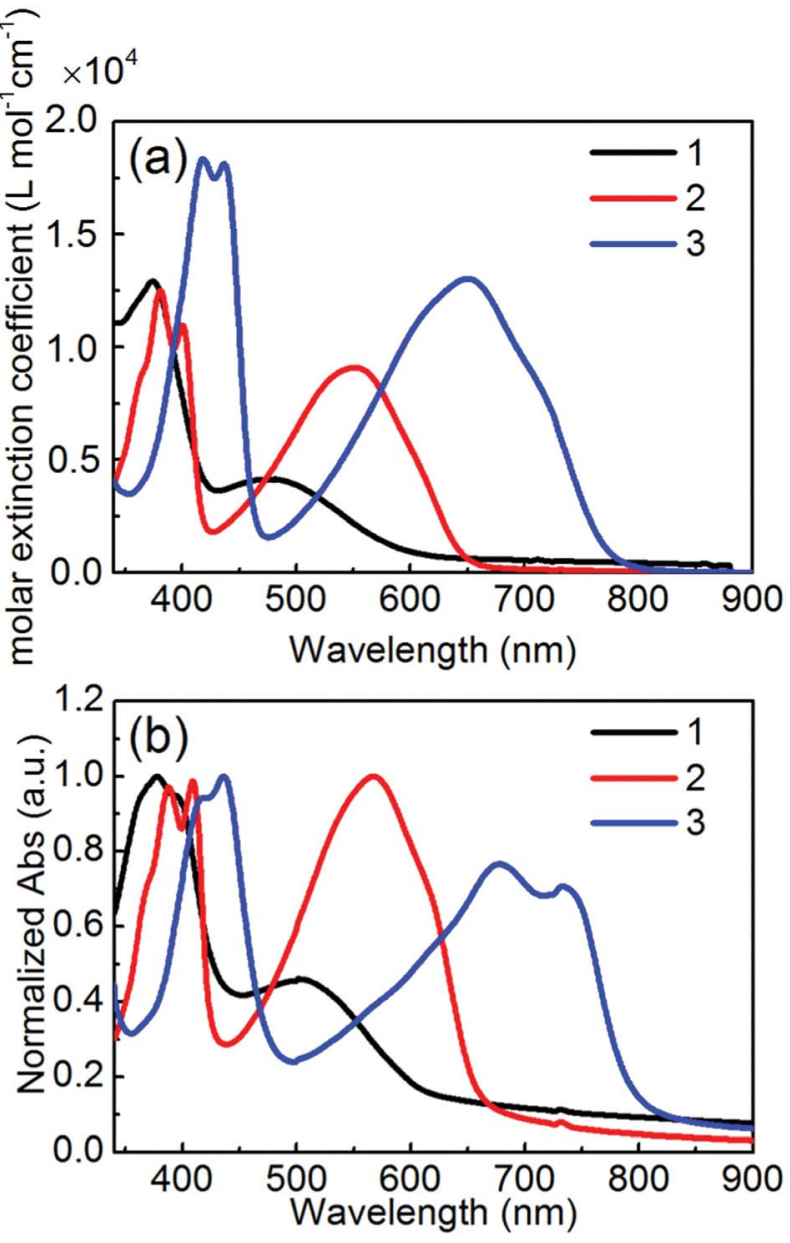

Fig. 3 UV-vis absorption spectra of $1-3$ for (a) $10^{-5} \mathrm{M} \mathrm{CHCl}_{3}$ solutions and (b) thin films spin-coated from $\mathrm{CHCl}_{3}$ solutions.

In general, the ambipolar characteristics for $\mathrm{Au}$ electrodes require a HOMO level above $-5.6 \mathrm{eV}$ and LUMO level below $-3.15 \mathrm{eV} .^{40}$ The HOMO and LUMO levels of 2 and 3 satisfy these conditions. Therefore, molecules 2 and 3 are expected to exhibit an ambipolar performance in OFETs.

\section{X-ray single-crystal structure analysis}

The X-ray structure analyses of 1-3 have been performed using single crystals grown by the slow diffusion of methanol into the chloroform solutions of $\mathbf{1}$ and $\mathbf{2}$ and chloroform into toluene solutions of 3 . The crystallographic data are listed in Table 2,

Table 1 Optical and electrochemical properties of 1-3

\begin{tabular}{llllll}
\hline & $\lambda_{\max }^{\text {sol. } a}\left(\varepsilon_{\max }{ }^{a}\right)[\mathrm{nm}]\left(\left[10^{4} \mathrm{M}^{-1} \mathrm{~cm}^{-1}\right]\right)$ & $\lambda_{\max }^{\mathrm{film} b}[\mathrm{~nm}]$ & $E_{\mathrm{g}}^{\text {opt.c }}[\mathrm{eV}]$ & $E_{\mathrm{HOMO}}^{\mathrm{CV}}[\mathrm{eV}]$ & $E_{\mathrm{LUMO}}^{\mathrm{CV}}[\mathrm{eV}]$ \\
\hline $\mathbf{1}$ & $395(1.29), 500(0.41)$ & 378,501 & 2.03 & -5.41 & -3.10 \\
$\mathbf{2}$ & $381(1.25), 401(1.10), 552(0.91)$ & $388,409,567$ & 1.88 & -5.21 & -3.35 \\
3 & $419(1.83), 437(1.81), 651(1.30)$ & $437,678,733$ & 1.57 & -5.07 & -3.38
\end{tabular}

${ }^{a}$ In $\mathrm{CHCl}_{3}$ solution. ${ }^{b}$ Spin-coat thin films. ${ }^{c}$ Estimated from the solution absorption onset. ${ }^{d}$ Estimated from cyclic voltammetry $v s$. $\mathrm{Fc} / \mathrm{Fc}^{+}$ $\left(E_{\mathrm{HOMO}}=-4.80 \mathrm{eV}\right) .{ }^{e} E_{\mathrm{g}}^{\mathrm{CV}}=E_{\mathrm{LUMO}}^{\mathrm{CV}}-E_{\mathrm{HOMO}}^{\mathrm{CV}}$ 

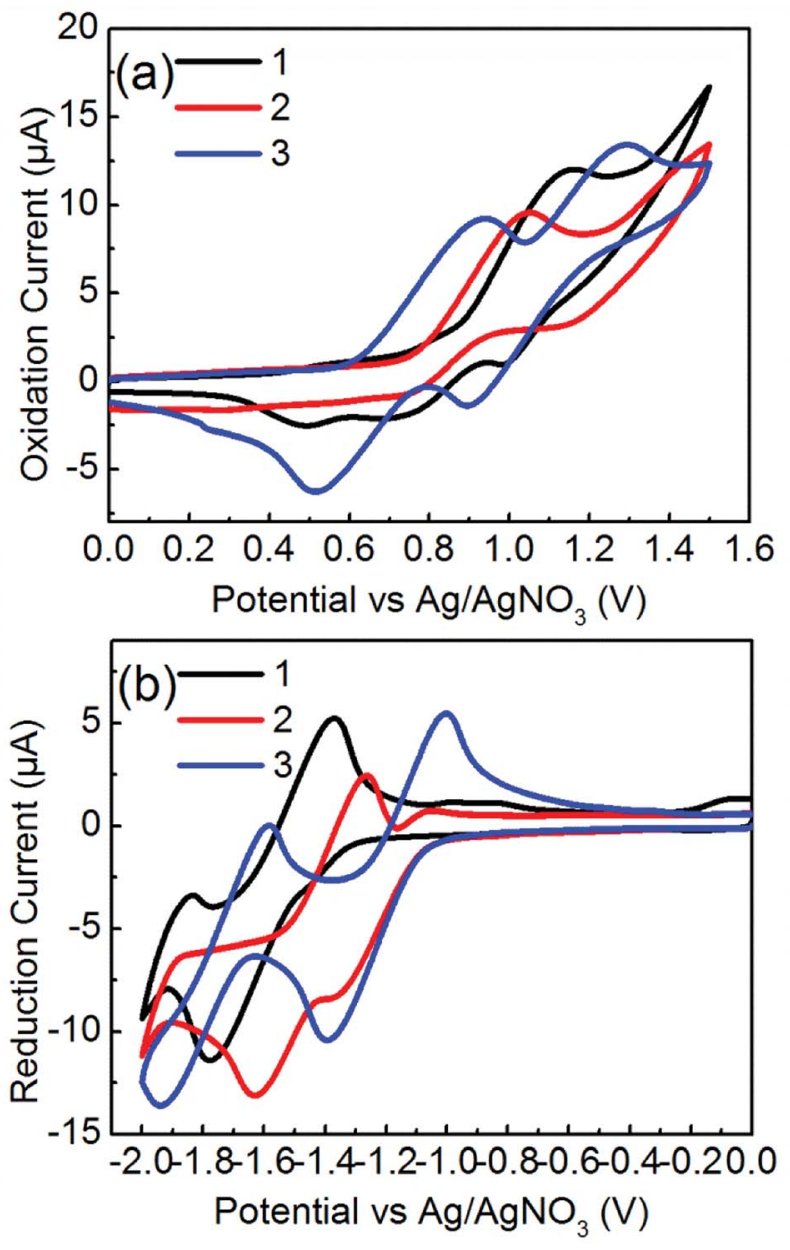

Fig. 4 Cyclic voltammograms of 1-3 measured in 0.1 $\mathrm{M} \mathrm{Bu}_{4} \mathrm{NPF}_{6}$ in $\mathrm{CH}_{2} \mathrm{Cl}_{2}$ at the scan rate of $100 \mathrm{mV} \mathrm{s}^{-1}$, (a) positive scans for oxidation steps and (b) negative scans for reducing steps.

and the molecular and crystal structures are shown in Fig. 5-7. Molecule 1 crystallizes in the monoclinic system with space group $P 2_{1} / c$. A half molecule, which is associated with the 2 -fold axis along the $c$ axis, is crystallographically independent (Fig. 5). Unlike the optimized structure estimated from the DFT calculation, the $\pi$-framework is almost planar in the solid state, and the alkyl chains are extended out of the planes. The molecules stack into one-dimensional slipped columnar structures along the $b$ axis with the interplanar spacing of $3.33 \AA$, in which the slip distances of $\mathbf{1}$ are $2.90 \AA$ along the molecular long axis and $2.30 \AA$ along the molecular short axis (Fig. 5(b)). Assuming the tight binding method, ${ }^{41}$ the calculated the HOMO and LUMO transfer integrals, $t_{\mathrm{p}}=68 \mathrm{meV}$ for HOMO and $t_{\mathrm{p}}=51 \mathrm{meV}$ for LUMO, also indicate a one-dimensional transport (Fig. 5(c)).

Molecule 2 crystallizes with the same $P 2_{1} / c$ space group as molecule 1, in which the two half molecules A and B are crystallographically independent (Fig. 6). As expected, the TII unit of the A and B molecules adopt planar conformations, and the alkyl chains are extended out of plane. In the crystal structure, molecules $\mathrm{A}$ and $\mathrm{B}$ are connected through the H-bonding between the $\alpha$-protons of thiophene and carbonyl oxygens to
Table 2 Crystallographic data for 1-3

\begin{tabular}{llll}
\hline & $\mathbf{1}$ & $\mathbf{2}$ & $\mathbf{3}$ \\
\hline Chemical formula & $\mathrm{C}_{28} \mathrm{H}_{34} \mathrm{~N}_{2} \mathrm{O}_{2}$ & $\mathrm{C}_{24} \mathrm{H}_{30} \mathrm{~N}_{2} \mathrm{O}_{2} \mathrm{~S}_{2}$ & $\mathrm{C}_{32} \mathrm{H}_{34} \mathrm{~N}_{2} \mathrm{O}_{2} \mathrm{~S}_{2}$ \\
Crystal system & Monoclinic & Monoclinic & Triclinic \\
Formula weight & 430.59 & 442.63 & 542.75 \\
Sharp & Red needle & Black plate & Black needle \\
Space group & $P 2_{1} / c$ & $P 2_{1} / c$ & $P(\overline{1})$ \\
$a(\AA)$ & $14.8546(3)$ & $19.2970(3)$ & $5.05526(9)$ \\
$b(\AA)$ & $4.93706(9)$ & $8.24241(10)$ & $8.31652(15)$ \\
$c(\AA)$ & $16.1007(4)$ & $15.6572(2)$ & $16.4731(3)$ \\
$\alpha\left(^{\circ}\right)$ & 90.0000 & 90.0000 & $79.8632(10)$ \\
$\beta\left(^{\circ}\right)$ & $92.2269(13)$ & 114.8240 & $87.7600(12)$ \\
$\gamma\left({ }^{\circ}\right)$ & 90.0000 & 90.0000 & $86.0505(10)$ \\
$V\left(\AA^{3}\right)$ & $1179.91(4)$ & $2260.24(6)$ & $679.88(3)$ \\
$Z$ & 2 & 4 & 1 \\
$D_{\text {cal }}(\mathrm{g}$ cm & \\
Data/parameters & 1.212 & 1.301 & 1.326 \\
Goodness of fit on $F_{0}{ }^{2}$ & $2150 / 145$ & $4124 / 271$ & $2436 / 172$ \\
$R_{1}{ }^{a} / R_{\mathrm{W}}{ }^{b}$ & 1.100 & 1.075 & 1.137 \\
Reflections used & $0.0359 / 0.1018$ & $0.0399 / 0.1094$ & $0.0475 / 0.1455$ \\
${ }^{a} R_{1}=\sum|| F_{0}|-| F_{\mathrm{c}}|| / \sum\left|F_{0}\right| \cdot{ }^{b} R_{\mathrm{W}}=\left[\sum \omega\left(\left|F_{0}\right|-\left|F_{\mathrm{c}}\right|\right)^{2} / \sum \omega F_{0}{ }^{2}\right.$ & $1 / 2$. \\
& & &
\end{tabular}

form infinite chains aligning along the $a+c$ direction (Fig. 5(b)). No noticeable intermolecular overlaps, desirable for chargetransport, are observed in the structure. Therefore, the calculated HOMO and LUMO transfer integrals are quite low: $t_{\mathrm{p} 1}=6 \mathrm{meV}$, $t_{\mathrm{p} 2}=3 \mathrm{meV}, t_{\mathrm{q}}=3 \mathrm{meV}, t_{\mathrm{c} 1}=2 \mathrm{meV}$ and $t_{\mathrm{c} 2}=2 \mathrm{meV}$ for HOMO integrals and $t_{\mathrm{p} 1}=2 \mathrm{meV}, t_{\mathrm{p} 2}=1 \mathrm{meV}$, and $t_{\mathrm{q}}=12 \mathrm{meV}$ for LUMO integrals (Fig. 6(c)). These small values imply the low charge-carrier mobilities of 2.

Molecule 3 crystallizes in a triclinic system with the space group $P(\overline{1})$, in which the half molecules are crystallographically independent (Fig. 7). The $\pi$-framework of 3 has a flat conformation, and the alkyl chains are extended in-plane. Similar to the structure of $\mathbf{1}$, the molecules make one-dimensional slipped stacks along the $a$ axis with the interplanar spacing of $3.40 \AA$, and the slip distances of 3 are $3.47 \AA$ along the molecular long axis and 1.52 $\AA$ along the molecular short axis. The $\pi$-stacks connected through the infinite H-bonding chains along the $b$ axis are aligned with a parallel orientation, which is indicative of the presence of side-by-side interactions in contrast to the structure of 1 . The calculated HOMO transfer integrals along the stacks are $t_{\mathrm{p}}=69 \mathrm{meV}, t_{\mathrm{q}}=2 \mathrm{meV}$, and $t_{\mathrm{c}}=2 \mathrm{meV}$ and the LUMO transfer integrals are $t_{\mathrm{p}}=57 \mathrm{meV}, t_{\mathrm{q}}=3 \mathrm{meV}$, and $t_{\mathrm{c}}=$ $3 \mathrm{meV}$ (Fig. 7(c)). These anisotropic intermolecular interactions also suggest that molecule 3 makes a one-dimensional transport.

\section{Field-effect transistor performance}

In order to investigate the charge transport properties of 1-3, we fabricated bottom-gate/top-contact OFET devices with Au as the source and drain electrodes. The thin films $(45 \mathrm{~nm})$ were thermally deposited on the tetratetracontane (TTC)-modified $\mathrm{SiO}_{2} / \mathrm{Si}$ substrates. All the molecules 1-3 exhibited typical ambipolar FET performances, and the corresponding data are summarized in Table 3. The transfer and output curves are provided in Fig. 8 and $\mathrm{S} 2, \dagger$ respectively. These results are 
(a)

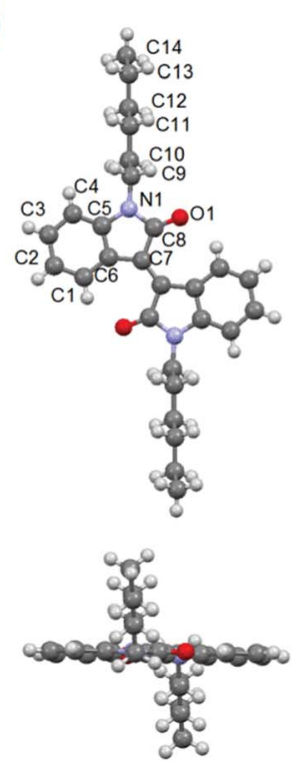

(b)

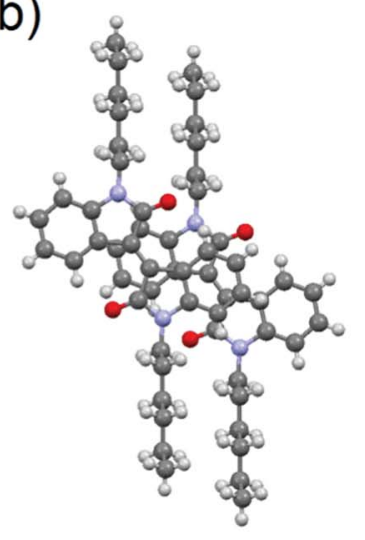

(c)

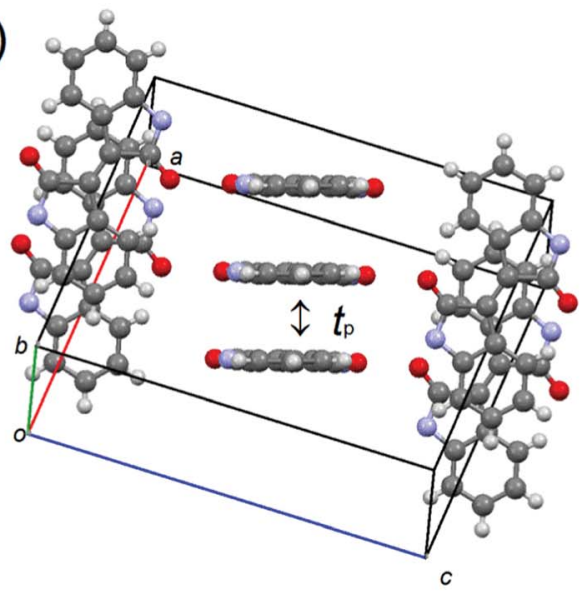

Fig. 5 (a) Molecular structure, (b) overlap mode, and (c) molecular packing of 1, in which alkyl chains are omitted for clarification.

because the energy levels of molecules 1-3 (Table 1) satisfy the requirements to display ambipolar characteristics $(-5.6$ to $-3.15 \mathrm{eV}) .^{40}$ Molecules 1 and 2 exhibited low hole and electron mobilities around $10^{-5}-10^{-4} \mathrm{~cm}^{2} \mathrm{~V}^{-1} \mathrm{~s}^{-1}$. In contrast, molecule 3 exhibited the highest hole mobility of $0.095 \mathrm{~cm}^{2} \mathrm{~V}^{-1} \mathrm{~s}^{-1}$ and electron mobility of $5.8 \times 10^{-3} \mathrm{~cm}^{2} \mathrm{~V}^{-1} \mathrm{~s}^{-1}$. These values are (a)

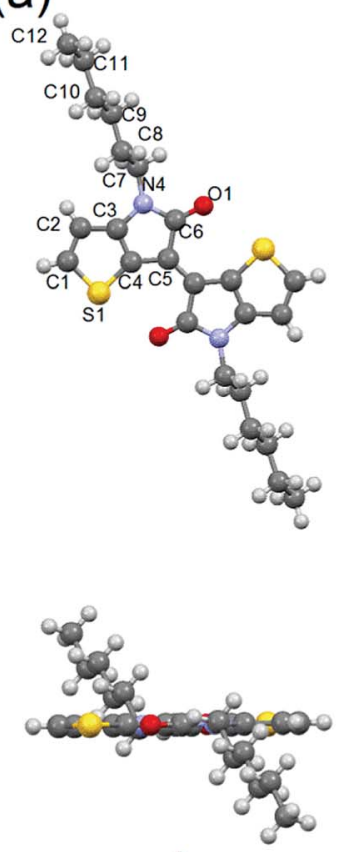

A
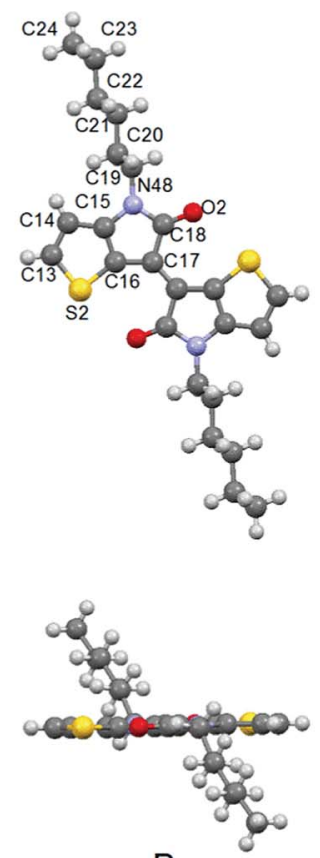

B

(b)

(c)
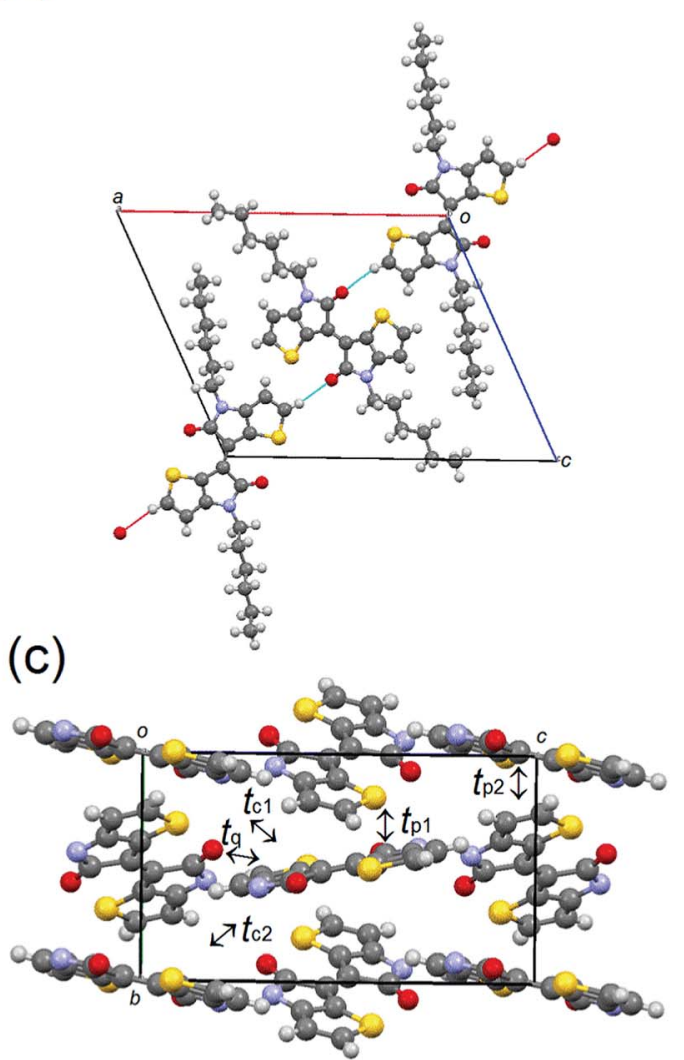

Fig. 6 (a) Molecular structure, (b) H-bonding chains along the a $+c$ direction, and (c) molecular packing of 2, in which the alkyl chains are omitted for clarification. 
(a) omitted for clarification.

(b)
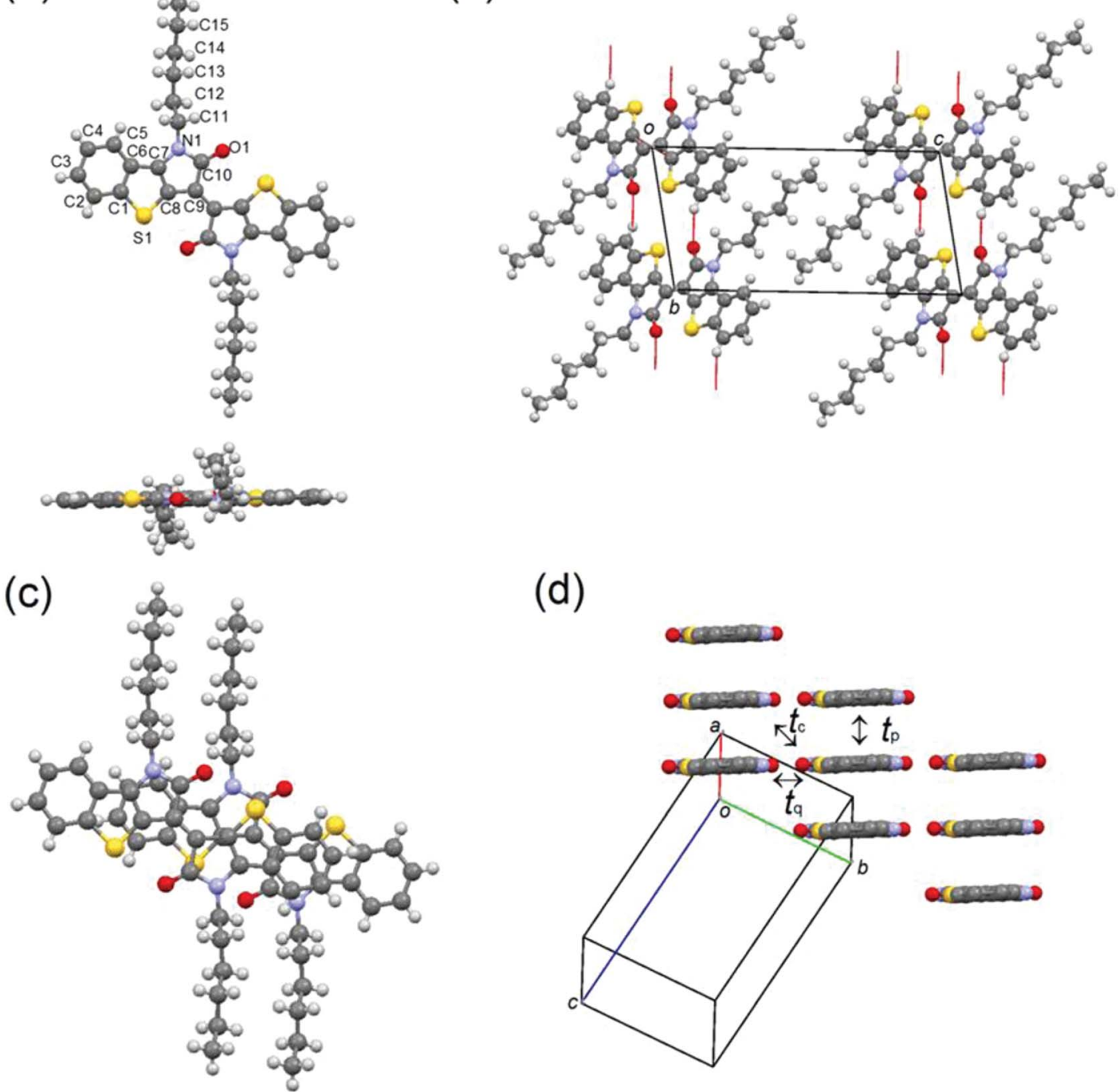

(d)

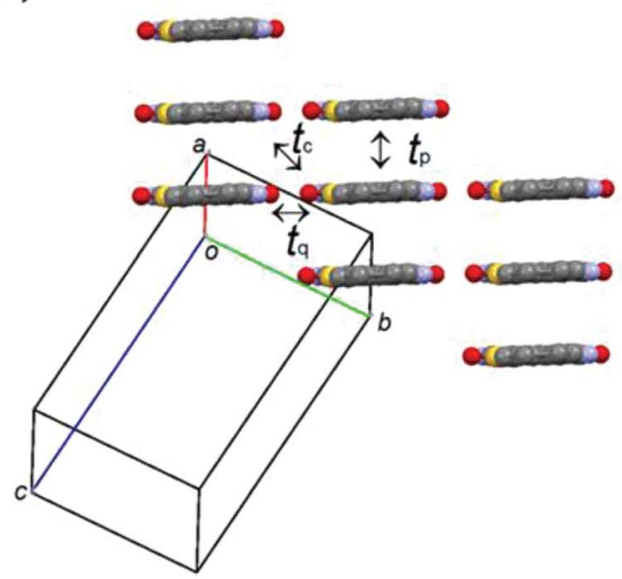

Fig. 7 (a) Molecular structure, (b) H-bonding chains along the $b$ axis, (c) overlap mode, and (d) molecular packing of 3, in which alkyl chains are

comparable or slightly improved compared to the TII-based copolymers $^{24,31}$ and the previously reported TII-based small molecules. ${ }^{28}$ This p-channel dominant character is because the HOMO level estimated from the CV measurement matches the Fermi level $(-5.13 \mathrm{eV})$ of the Au electrode ${ }^{42}$ therefore, facilitating the effective hole injection from the Au electrodes to the thin film.

The structure analyses of $\mathbf{1}$ and $\mathbf{3}$ indicate a similar onedimensional transport system. However, the higher mobilities are achieved in the thin film of 3 . This result suggests that the increased $\pi$-conjugation of the BTII unit enables significant co-facial $\pi-\pi$ interactions, realizing a tight intermolecular packing.

In general, the substrate temperature during thermal evaporation influences microstructure and morphology in thin film, and thus we deposited thin film of 3 at an elevated temperature $\left(80{ }^{\circ} \mathrm{C}\right.$ and $100{ }^{\circ} \mathrm{C}$ ) on the octadecyltrimethoxysilane (OTMS)modified $\mathrm{SiO}_{2} / \mathrm{Si}$ substrates. The transfer and output curves are listed in Fig. 8 and S2. $\dagger$ The thin film of 3 deposited on the OTMS-modified substrate at $80^{\circ} \mathrm{C}$ exhibited p-type performance with higher hole mobility of $\mu_{\mathrm{h}, \max }=0.18 \mathrm{~cm}^{2} \mathrm{~V}^{-1} \mathrm{~s}^{-1}$ than that of the device on the TTC-modified substrate. The SAM modification has strong impact of carrier transport polarity: the observed ambipolar behavior on the TTC-modified substrate beneficial for electron-transport basically accords with the previous report. ${ }^{43}$

\section{Morphology of thin films}

In order to clarify the difference in the FET properties, the thin film microstructure and surface topology of 1-3 on the TTCmodified substrates and 3 on the OTMS-modified substrates, XRD patterns (Fig. 9) and AFM images (Fig. 10) were examined. All the XRD patterns show the primary sharp and intense peaks corresponding to the $d$-spacings of $15.0 \AA$ for $1,14.5 \AA$ for $2,17.0$ $\AA$ for 3 on the TTC-modified substrates and $16.5 \AA$ at r.t, $16.2 \AA$ at $80{ }^{\circ} \mathrm{C}$, and $16.4 \AA$ at $100{ }^{\circ} \mathrm{C}$ for 3 on the OTMS-modified substrates. Considering the bulk crystal lattice estimated from 
Table 3 OFET characterization for $1-3$

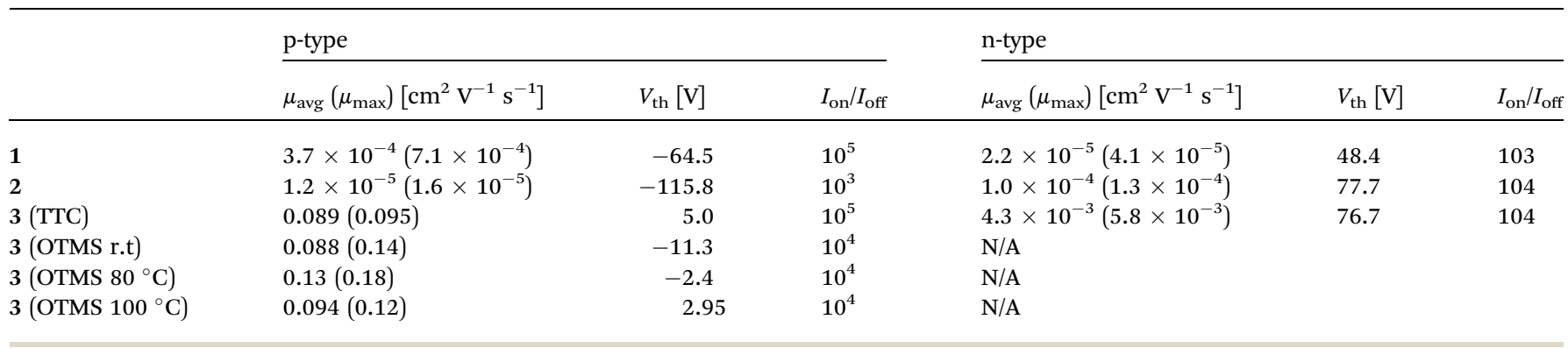

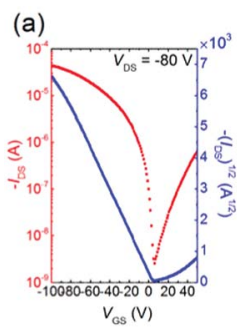

(b)

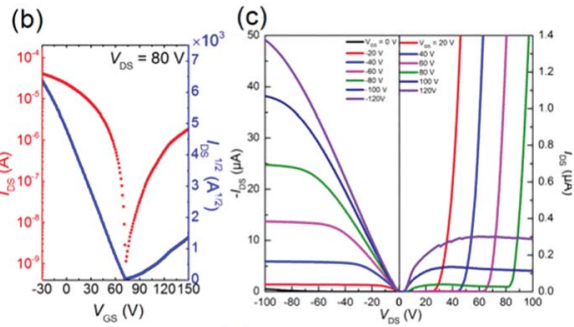

(d)
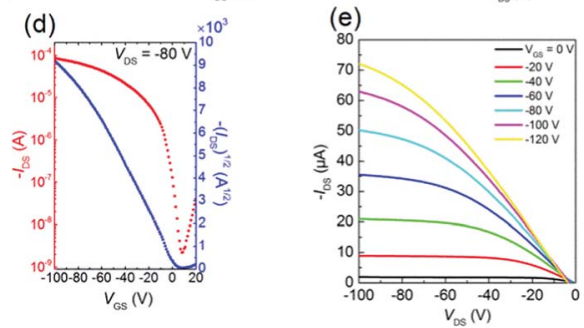

Fig. 8 (a) p-type and (b) n-type transfer curves, and (c) output curve for the TTC modified device of 3. (d) p-type transfer curve and (e) output curve for the OTMS modified substrate elevated at $80^{\circ} \mathrm{C}$ of 3 .

the single-crystal X-ray structure analyses, these $d$-spacings approximately correspond to $a$ for $\mathbf{1}, c \sin \beta$ for 2 , and $b+c$ for 3 on the TTC-modified substrates and $c$ at r.t, $c \sin \alpha$ at $80^{\circ} \mathrm{C}$, and $c \sin \beta$ at $100{ }^{\circ} \mathrm{C}$ for 3 on the OTMS-modified substrates. Thus, in the layered out-of-plane direction, the molecular $\pi$-frameworks of 1-3 are tilted, and both sets of hexyl chains stand on the substrate; tilt angles are roughly estimated to be $47^{\circ}$ for $1,9^{\circ}$ for $2,20^{\circ}$ for 3 on the TTC-modified substrates and $35^{\circ}$ at r.t, $30^{\circ}$ at $80{ }^{\circ} \mathrm{C}$, and $34^{\circ}$ at $100{ }^{\circ} \mathrm{C}$ for 3 on the OTMS-modified substrates. In general, the small tilt angle is one of the factors for maximizing the carrier mobility since the charge-transport channel is parallel to the substrate. ${ }^{44}$ Therefore, the large tilt angle of $\mathbf{1}$ is unfavorable for charge carrier transport, thus leading to the low mobility. In contrast, thin film of 2 showed low mobility in spite of the smallest tilt angle among 1-3, which would be attributed to poor transfer integrals calculated from the single-crystal X-ray structure analyses. The higher mobility of $\mathbf{3}$ in comparison with $\mathbf{1}$ and $\mathbf{2}$ are owing to the tilt angles around $20-34^{\circ}$ with large transfer integrals coming from dense molecular packing and molecular size.

We next compared the AFM height images of 1-3 in order to understand the FET performances of 1-3. The different FET properties should also originate from the surface morphologies of the thin films, because microscopic thin film structures have a large impact on the charge-transport. ${ }^{45}$ The thin film of 1 showed the largest plate-like grains among molecules 1-3, however, these grains are separated by obviously disconnected and defective boundaries bearing void-like structures, indicative of a high RMS value. This poor surface morphology is the origin of the low mobilities of $\mathbf{1}$ as well as the large tilt angle normal to the substrate. Similarly, the thin film of 2 exhibited discontinuous plate-like domains, although the surface roughness was even reduced. This defective thin film morphology is responsible for the low carrier mobilities as well as the smaller intermolecular overlaps. The most important change was
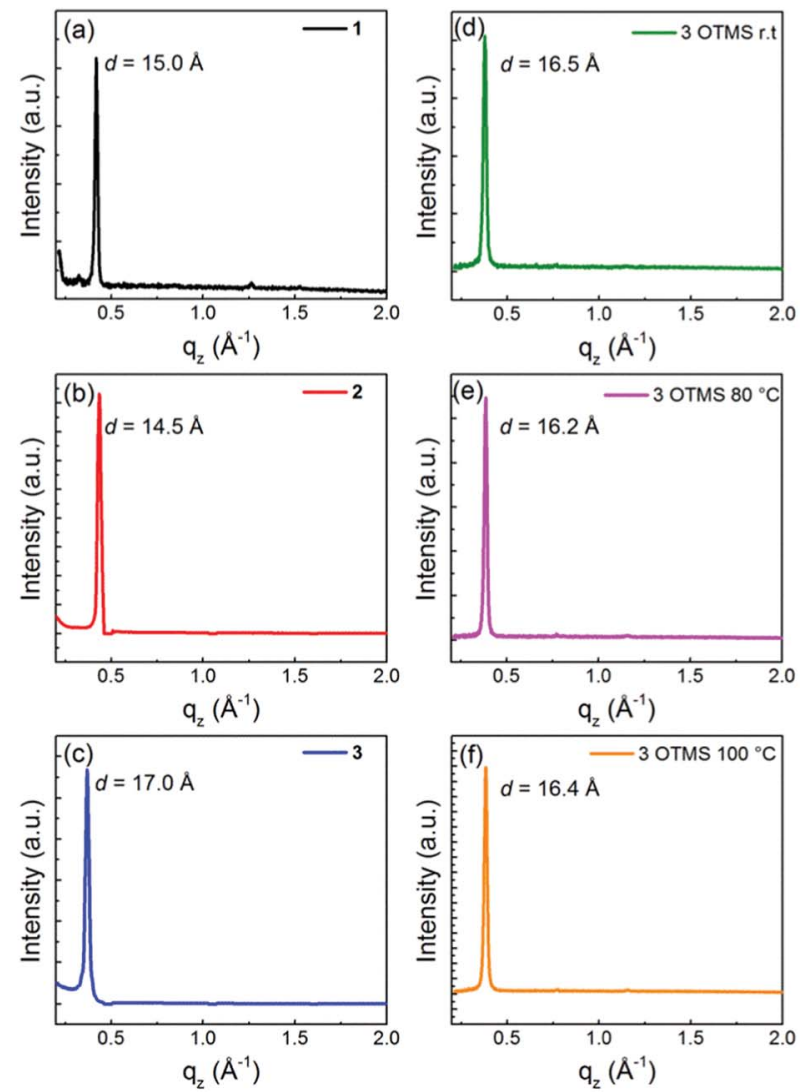

Fig. 9 X-ray diffraction patterns of (a) 1 , (b) 2 and (c) 3 thin films ( $45 \mathrm{~nm}$ ) deposited on TTC $(20 \mathrm{~nm})$ modified substrates and thin film of 3 deposited elevated substrate temperature at (d) r.t, (e) $80^{\circ} \mathrm{C}$, and (f) $100^{\circ} \mathrm{C}$. 

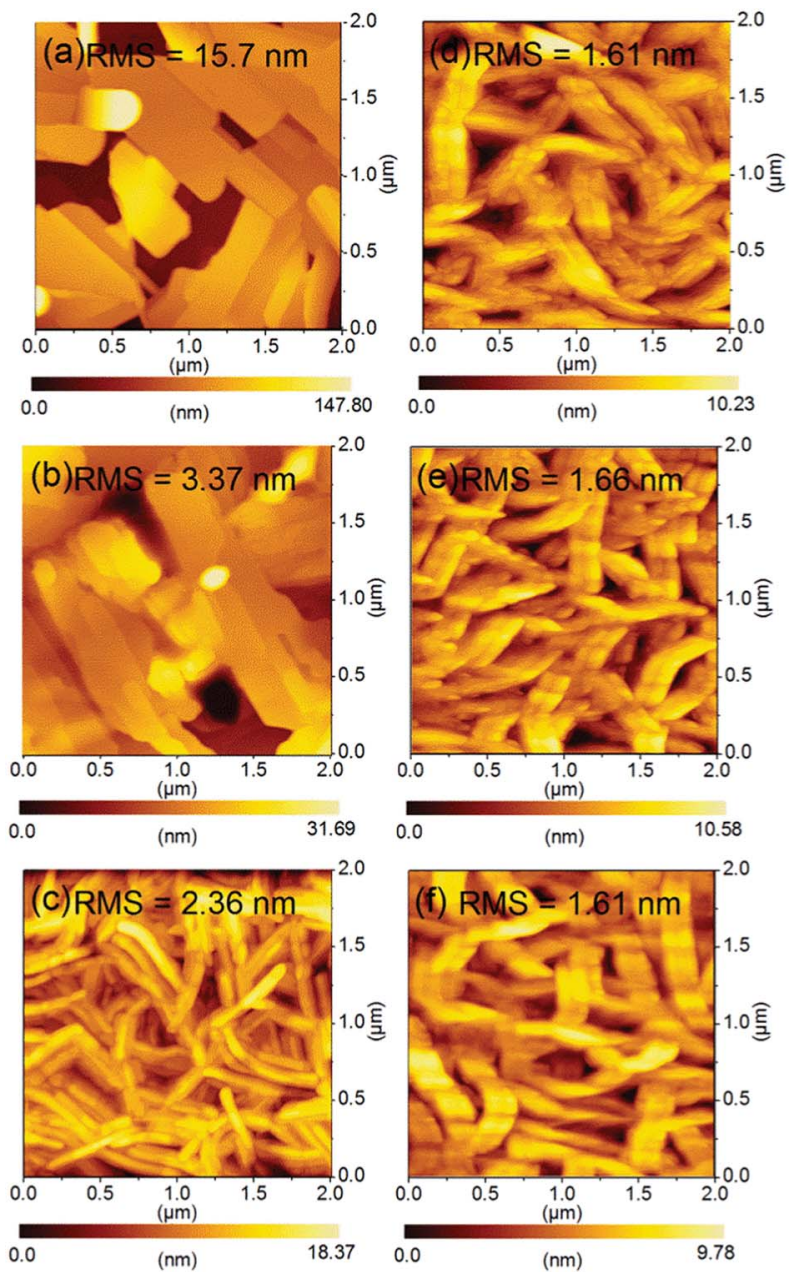

Fig. 10 AFM images of thin films $(45 \mathrm{~nm})$ of (a) 1, (b) 2 and (c) 3 thermally evaporated on TTC $(20 \mathrm{~nm})$ modified substrates and thin film of 3 deposited elevated substrate temperature at (d) r.t, (e) $80{ }^{\circ} \mathrm{C}$, and (f) $100{ }^{\circ} \mathrm{C}$.

observed in the thin film of 3 . Molecule 3 formed wellinterconnected nanorod-like crystalline grains with the lowest RMS value. The fabrication conditions for the thin films of 1-3 are the same. Therefore, the extended $\pi$-conjugation of 3 would contribute to forming the crystalline grains which are laterally grown via an island-like mechanism. ${ }^{46}$ As a result, the obtained surface morphology of 3 consists of nanorod-like crystalline grains, which makes dense and smoothly connected domains preferable for charge transport. All thin films of 3 deposited on the OTMS-modified substrate are consisted of larger nanorod-like crystalline grains compared with that of 3 on the TTC-modified substrate, especially when comparing the deposited films at r.t. (Fig. 10(c)-(f)), suggesting SAM treatment has a significant effect on film formation. Among thin films on the OTMS-modified substrate, the dense domains and interconnected grain boundaries are formed in addition to the smallest tilt angle in thin film deposited at $80{ }^{\circ} \mathrm{C}$. This is responsible for the highest mobilities of $0.18 \mathrm{~cm}^{2} \mathrm{~V}^{-1} \mathrm{~s}^{-1}$ of 3 . These findings concerning the thin-film microstructures of 1-3 would suggest that the molecular $\pi$-surface has a strong impact on the film-formation mechanism.

\section{Conclusions}

In this study, we have synthesized and characterized three sets of molecules 1-3 with hexyl side chains in order to understand the structure-property relationship in the FETs. In particular, the BTII of 3 is a novel $\pi$-expanded framework of TII. The absorption spectra are remarkably red-shifted in the order of $\mathbf{1}<\mathbf{2}<\mathbf{3}$ along with the enhanced molar extinction coefficient in the low-energy region. The high-lying HOMO and low-lying LUMO levels are realized by the molecular planarity and extended $\pi$-conjugation, and then the smaller bandgap of 3 is realized. The single crystal structures of 1-3 were analyzed. Molecules $\mathbf{1}$ and $\mathbf{3}$ are packed into one-dimensional columns composed of co-facial intermolecular overlaps whereas molecule 2 does not form noticeable intermolecular overlaps. The OFET of 1-3 on the TTC-modified substrates exhibited ambipolar characteristics. Notably, the thin film of 3 on the TTC modified device showed a p-dominant performance with the highest hole mobility of $0.095 \mathrm{~cm}^{2} \mathrm{~V}^{-1} \mathrm{~s}^{-1}$ and electron mobility of $5.8 \times 10^{-3}$ $\mathrm{cm}^{2} \mathrm{~V}^{-1} \mathrm{~s}^{-1}$, which is well associated with the HOMO energy level of 3. On the OTMS-modified substrate, the devices of 3 showed a p-type performance with the mobility up to $0.18 \mathrm{~cm}^{2}$ $\mathrm{V}^{-1} \mathrm{~S}^{-1}$. Systematic evaluation of the FET performance on the TTC-modified substrate by comparing three sets of molecules 13 concluded that the $\pi$-expansion of the TII unit, namely the BTII unit, influences the electronic structure, packing motif in the bulk crystal, and thin film structure, resulting in the improved FET performance. The present study provides a better understanding of the structure-property relationship of the TIIbased molecules for the development of high performance ambipolar OFETs.

\section{Acknowledgements}

This study was partly supported by a fund from the Development of Human Resources in Science and Technology of the Japan Science and Technology Agency, JST (for H. M.) and a Grant-in-Aid for Scientific Research (C) (No. 26410087) from the Ministry of Education, Culture, Sports, Science and Technology (for M. A). The authors are grateful to the Center for Advanced Materials, Tokyo Institute of Technology, for the microanalysis.

\section{Notes and references}

1 C. L. Wang, H. L. Dong, W. P. Hu, Y. Q. Liu and D. B. Zhu, Chem. Rev., 2012, 112, 2208-2267.

2 A. R. Murphy and J. M. J. Fréchet, Chem. Rev., 2007, 107, 1066-1096.

3 H. Klauk, Chem. Soc. Rev., 2010, 39, 2643-2666.

4 J. E. Anthony, A. Facchetti, M. Heeney, S. R. Marder and X. Zhan, Adv. Mater., 2010, 22, 3876-3892.

5 J. Zaumseil and H. Sirringhaus, Chem. Rev., 2007, 107, 12961323.

6 H. Yan, Z. Chen, Y. Zheng, C. Newman, J. R. Quinn, F. Dötz, M. Kastler and A. Facchetti, Nature, 2009, 457, 679-686. 
7 J. Li, Y. Zhao, H. S. Tan, Y. Guo, C.-A. Di, G. Yu, Y. Liu, M. Lin, S. H. Lim, Y. Zhou, H. Su and B. S. Ong, Sci. Rep., 2012, 2, 754-763.

8 G. Kim, S.-J. Kang, G. K. Dutta, Y.-K. Han, T. J. Shin, Y.-Y. Noh and C. Yang, J. Am. Chem. Soc., 2014, 136(26), 9477-9483.

9 C. Luo, A. K. K. Kyaw, L. A. Perez, S. Patel, M. Wang, B. Grimm, G. C. Bazan, E. J. Kramer and A. J. Heeger, Nano Lett., 2014, 14(5), 2764-2771.

10 S. Fabiano, H. Usta, R. Forchheimer, X. Crispin, A. Facchetti and M. Berggren, Adv. Mater., 2014, 26(44), 7438-7443.

11 K.-J. Baeg, J. Kim, D. Khim, M. Caironi, D.-Y. Kim, I.-K. You, J. R. Quinn, A. Facchetti and Y.-Y. Noh, ACS Appl. Mater. Interfaces, 2011, 3(8), 3205-3214.

12 M. A. McCarthy, B. Liu, E. P. Donoghue, I. Kravchenko, D. Y. Kim, F. So and A. G. Rinzler, Science, 2011, 332, 570573.

13 M. C. Gwinner, D. Kabra, M. Roberts, T. J. Brenner, B. H. Wallikewitz, C. R. McNeill, R. H. Friend and H. Sirringhaus, Adv. Mater., 2012, 24(20), 2728-2734.

14 J. Lee, A.-R. Han, J. Kim, Y. Kim, J. H. Oh and C. Yang, J. Am. Chem. Soc., 2012, 134(51), 20713-20721.

15 J. Lee, A.-R. Han, H. Yu, T. J. Shin, C. Yang and J. H. Oh, J. Am. Chem. Soc., 2013, 135(25), 9540-9547.

16 X. Liu, Y. Sun, B. B. Y. Hsu, A. Lorbach, L. Qi, A. J. Heeger and G. C. Bazan, J. Am. Chem. Soc., 2014, 136(15), 5697-5708.

17 G. C. Welch, L. A. Perez, C. V. Hoven, Y. Zhang, X.-D. Dang, A. Sharenko, M. F. Toney, E. J. Kramer, T.-Q. Nguyen and G. C. Bazan, J. Mater. Chem., 2011, 21, 12700-12709.

18 S. Xu, N. Ai, J. Zheng, N. Zhao, Z. Lan, L. Wen, X. Wang, J. Pei and X. Wan, RSC Adv., 2015, 5, 8340-8344.

19 J. Zhang, G. Wu, C. He, D. Deng and Y. Li, J. Mater. Chem., 2011, 21, 3768-3774.

20 T. Higashino, S. Kumeta, S. Tamura, Y. Ando, K. Ohmori, K. Suzuki and T. Mori, J. Mater. Chem. C, 2015, 3, 1588-1594.

21 O. Pitayatanakul, T. Higashino, T. Kadoya, M. Tanaka, H. Kojima, M. Ashizawa, T. Kawamoto, H. Matsumoto, K. Ishikawa and T. Mori, J. Mater. Chem. C, 2014, 2, 93119317.

22 E. Wang, W. Mammo and M. R. Andersson, Adv. Mater., 2014, 26, 1801-1826.

23 R. S. Ashraf, A. J. Kronemeijer, D. I. James, H. Sirringhaus and I. McCulloch, Chem. Commun., 2012, 48, 3939-3941.

24 Y. Koizumi, M. Ide, A. Saeki, C. Vijayakumar, B. Balan, M. Kawamoto and S. Seki, Polym. Chem., 2013, 4, 484-494.

25 G. K. Dutta, A.-R. Han, J. Lee, Y. Kim, J. H. Oh and C. Yang, Adv. Funct. Mater., 2013, 23, 5317-5325.

26 C.-M. Chen, S. Sharma, Y.-L. Li, J.-J. Lee and S.-A. Chen, J. Mater. Chem. C, 2015, 3, 33-36.

27 R. R. Dasari, A. Dindar, C. K. Lo, C.-Y. Wang, C. Quinton, S. Singh, S. Barlow, C. F. Hernandez, J. R. Reynolds, B. Kippelen and S. R. Marder, Phys. Chem. Chem. Phys., 2014, 16, 19345-19350.

28 T. Odajima, M. Ashizawa, Y. Konosu, H. Matsumoto and T. Mori, J. Mater. Chem. C, 2014, 2, 10455-10467.

29 G. W. P. V. Pruissen, F. Gholamrezaie, M. M. Wienk and R. A. J. Janssen, J. Mater. Chem., 2012, 22, 20387-20393.
30 M. S. Chen, J. R. Niskala, D. A. Unruh, C. K. Chu, O. P. Lee and J. M. Fréchet, Chem. Mater., 2013, 25, 4088-4096.

31 M. Ide, Y. Koizumi, A. Saeki, Y. Izumiya, H. Ohkita, S. Ito and S. Seki, J. Phys. Chem. C, 2013, 117, 26859-26870.

32 M. Karakawa and Y. Aso, Macromol. Chem. Phys., 2013, 214, 2388-2397.

33 M. Karakawa and Y. Aso, RSC Adv., 2013, 3, 16259-16263.

34 M. Ide, Y. Koizumi, A. Saeki and S. Seki, J. Photopolym. Sci. Technol., 2013, 26(2), 217-221.

35 H.-J. Yun, H. H. Choi, S.-K. Kwon, Y.-H. Kim and K. Cho, ACS Appl. Mater. Interfaces, 2015, 7, 5898-5906.

36 L. A. Estrada, D. Y. Liu, D. H. Salazar, A. L. Dyer and J. R. Reynolds, Macromolecules, 2012, 45, 8211-8220.

37 J. Youn, M.-C. Chen, Y.-J. Liang, H. Huang, R. P. Ortiz, C. Kim, C. Stern, T.-S. Hu, L.-H. Chen, J.-Y. Yan, A. Facchetti and T. J. Marks, Chem. Mater., 2010, 22, 50315041.

38 M. J. Frisch, G. W. Trucks, H. B. Schlegel, G. E. Scuseria, M. A. Robb, J. R. Cheeseman, G. Scalmani, V. Barone, B. Mennucci, G. A. Petersson, H. Nakatsuji, M. Caricato, X. Li, H. P. Hratchian, A. F. Izmaylov, J. Bloino, G. Zheng, J. L. Sonnenberg, M. Hada, M. Ehara, K. Toyota, R. Fukuda, J. Hasegawa, M. Ishida, T. Nakajima, Y. Honda, O. Kitao, H. Nakai, T. Vreven, J. A. Montgomery Jr, J. E. Peralta, F. Ogliaro, M. Bearpark, J. J. Heyd, E. Brothers, K. N. Kudin, V. N. Staroverov, R. Kobayashi, J. Normand, K. Raghavachari, A. Rendell, J. C. Burant, S. S. Iyengar, J. Tomasi, M. Cossi, N. Rega, N. J. Millam, M. Klene, J. E. Knox, J. B. Cross, V. Bakken, C. Adamo, J. Jaramillo, R. Gomperts, R. E. Stratmann, O. Yazyev, A. J. Austin, R. Cammi, C. Pomelli, J. W. Ochterski, R. L. Martin, K. Morokuma, V. G. Zakrzewski, G. A. Voth, P. Salvador, J. J. Dannenberg, S. Dapprich, A. D. Daniels, Ö. Farkas, J. B. Foresman, J. V. Ortiz, J. Cioslowski and D. J. Fox, The molecular orbital calculation was carried out using the Gaussian 09, Revision B.01, Gaussian, Inc., Wallingford CT, 2009.

39 J. Pommerehne, H. Vestweber, W. Guss, R. F. Mark, H. Bässeles, M. Porsch and J. Daub, Adv. Mater., 1995, 7, 551-554.

40 M. L. Tang, A. D. Reichardt, P. Wei and Z. Bao, J. Am. Chem. Soc., 2009, 131, 5264.

41 T. Mori, A. Kobayashi, Y. Sasaki, H. Kobayashi, G. Saito and H. Inokuchi, Bull. Chem. Soc. Jpn., 1984, 57, 627-633.

42 H. B. Michaelson, J. Appl. Phys., 1977, 48, 4729-4733.

43 M. Irimia-Vladu, E. D. Głowacki, P. A. Troshin, G. Schwabegger, L. Leonat, D. K. Susarova, O. Krystal, M. Ullah, Y. Kanbur, M. A. Bodea, V. F. Razumov, H. Sitter, S. Bauer and N. S. Sariciftci, Adv. Mater., 2012, 24, 375-380. 44 T. Kakinuma, H. Kojima, M. Ashizawa, H. Matsumoto and T. Mori, J. Mater. Chem. C, 2013, 1, 5395-5401.

45 H. N. Tsao and K. Müllen, Chem. Soc. Rev., 2010, 39, 23722386.

46 J. A. Venebles, G. D. T. Spiller and M. Hanbücken, Rep. Prog. Phys., 1984, 47, 399-459. 